baseline WHO FC have no effects on the prognosis of CTEPH in patients with APS.

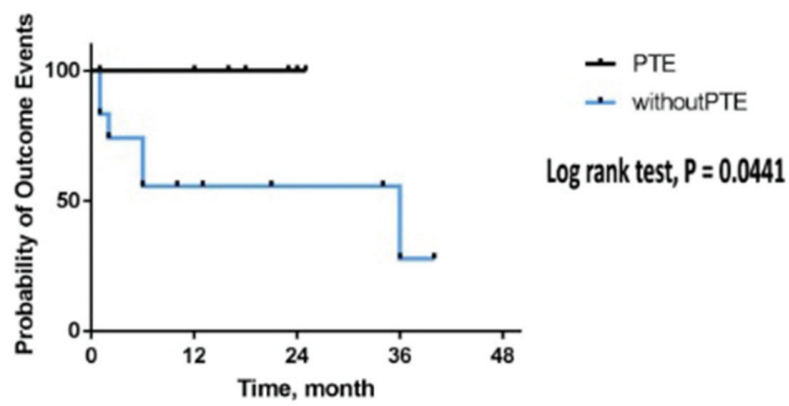

Abstract OP0355 - Figure 1 Kaplan-Meier survival curves of APS patients associated CTEPH after treatment (anticoagulation and/or PTE).

Conclusions: After a full specialised and multidisciplinary risk-benefit evaluation to limit the risk of thrombosis or bleeding and to manage possible thrombocytopenia, for those CTEPH developed in APS patients, PTE is a curative resolution. Disclosure of Interest: None declared DOI: 10.1136/annrheumdis-2018-eular.4044

\section{OP0356 PLASMABLAST PROLIFERATION IS ASSOCIATED WITH TOLL LIKE RECEPTOR 7 POLYMORPHISMS AND UPREGULATION OF TYPE I INTERFERON, CONTRIBUTING TO THE ANTIBODY PRODUCTION IN ANTIPHOSPHOLIPID SYNDROME}

R. Hisada, M. Kato, E. Sugawara, Y. Fujieda, K. Oku, T. Bohgaki, O. Amengual, S. Yasuda, T. Atsumi. Department of Rheumatology, Endocrinology and Nephrology, Faculty of Medicine and Graduate School of Medicine, Hokkaido University, Sapporo City, Japan

Background: Antiphospholipid antibodies (aPL) as pathogenic autoantibodies in systemic lupus erythematosus (SLE) and antiphospholipid syndrome (APS) are supported by a number of clinical, ex vivo and animal studies. Nevertheless, aPL are not eliminated by corticosteroid administration or immunosuppression. Novel therapy targeting aPL production is currently unmet needs, in contrast, little is known on its pathological mechanism.

Objectives: This study aimed to clarify the mechanism of aPL production by lymphocyte subset analysis, genomic analysis and ex vivo experiments.

Methods: B cell and T cell subsets, a total of 21 subsets, were evaluated in peripheral blood mononuclear cells (PBMC) of 26 primary APS (PAPS), 18 SLEassociated APS (SLE/APS) patients and 10 healthy controls by flow cytometry. Twenty-one single nucleotide polymorphisms (SNP), which were shown to be associated with autoimmune or thrombotic diseases, were analysed in genomic DNA of those patients by TaqMan genotyping assay. Interferon (IFN) score was calculated based on the mRNA expression of Ly6e, Mx1, IFIT1 and IFIT3 in PBMC. To evaluate the aPL-producing capability of plasmablasts, PBMC obtained from APS patients were cultured following depletion of CD19+CD20+or CD19+CD20 cells and the culture supernatants were applied to aPL measurements by enzyme-linked immunosorbent assay and cell assay using $\beta 2 \mathrm{GPI} / \mathrm{HLA}$ DR7 overexpressing HEK293T cells. ${ }^{1}$

Results: In PAPS and SLE/APS patients, plasmablasts, Th2 cells and Th17 cells were increased while pre- and post- switched memory $B$ cells, regulatory $B$ cells and regulatory $\mathrm{T}$ cells were decreased compared to healthy controls. Genomic analysis revealed that the increase of plasmablasts $(p=0.032)$ and the decrease of memory B cells ( $p=0.013$ ) were more pronounced in patients with a risk allele of SNP in toll like receptor 7 (TLR7) gene (rs3853839). IFN score was significantly higher in the TLR7 SNP risk allele carriers, confirming the downstream signalling of TLR7 $(\mathrm{p}=0.029)$. Ex vivo experiments showed that $\mathrm{aPL}$, including anti-cardiolipin//2-glycoprotein I-HLA class II complexes -IgG and -IgM, were present in the culture supernatant of CD19+CD20+depleted PBMC from APS patients, but not in that of CD19+CD20 depleted cells.

Conclusions: Our data indicate an important role of plasmablasts in the production of aPL. Furthermore, plasmablast proliferation was associated with TLR 7 and type I IFN, suggesting a common pathophysiology in SLE and APS. Targeting plasmablasts might be a novel, immunological therapeutic approach in the treatment of APS.

\section{REFERENCE:}

[1] Tanimura K, et al. $\beta 2-$ Glycoprotein I/HLA class II complexes are novel autoantigens in antiphospholipid syndrome. Blood 2015.
Disclosure of Interest: None declared

DOI: 10.1136/annrheumdis-2018-eular.2816

SATURDAY, 16 JUNE 2018

The links between gout and kidney function

\begin{tabular}{l|l}
\hline OP0357 & HYPERECHOIC DEPOSITS IN THE RENAL MEDULLA \\
ARE ASSOCIATED WITH SEVERE GOUT AND \\
DECREASED EGFR: A TRANSVERSAL STUDY IN 503 \\
VIETNAMESE PATIENTS
\end{tabular}

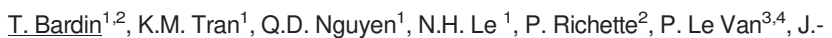
M. Correas ${ }^{5}$, M. Resche-Rigon ${ }^{6}{ }^{1}$ French-Vietnamese Gout Research Center, Vien Gut general clinic, Ho Chi Minh City, Viet Nam; ${ }^{2}$ Rheumatology, hôpital Lariboisière, Paris, France; ${ }^{3}$ Radiology, Cho Ray Hospital; ${ }^{4}$ university of Medicine and Pharmacy, Ho Chi Minh City, Viet Nam; ${ }^{5}$ radiology, Hôpital Necker, ${ }^{6}$ Biostatistics, hôpital Saint Louis, Paris, France

Background: Renal medulla crystal deposits have been demonstrated by pathology in severe gout but little studied by ultrasound (US) scan.

Objectives: To assess the frequency of hyperechoic renal medulla (HERM) in gouty patients and factors associated with their development.

Methods: Renal US scan using a Ecube 9 echograph (Alpinion S. Korea), was performed in gout patients (ACR/EULAR criteria) consecutively seen at the Vien Gut general clinic, Ho Chi Minh City, Vietnam, and receiving no ULT at presentation. Age and sex of patients, gout features, associated diseases, serum (S) uric acid (UA), eGFR (MDRD), urinary lab stick parameters, urine UA/creatinine ratio, and fractional clearance of urate (FCU) were recorded. Patients with HERM were counted and compared with those who had no medullary deposits by the Wilcoxon rank sum test for continuous varables and the Fischer exact test for categorical variables. Multivariable logistic model was used to assess relation between variables at inclusion in the study and presence of medulla deposits.

Results: 503 consecutive patients $(500$ males $)$ were included. They had a median age of 46 years, median BMl of $25 \mathrm{~kg} / \mathrm{m} 2$, median gout duration of 4 years. $280(56 \%)$ had clinical tophi, $154(31 \%)$ urate arthropathy, $\left.28 ;{ }^{5} 6 \%\right)$ urolithiasis, $112(22 \%)$ hypertension, $58(11.5 \%)$ type 2 diabetes, $5(1 \%)$ coronary heart disease. Their median eGFR was $78 \mathrm{ml} / \mathrm{min}$, SUA 423 micromol/L, FCU 0.063 , urine $\mathrm{UA} /$ creatinine ratio 0.253 , urinary $\mathrm{pH} 6$.

Diffuse and bilateral HERM on the $\mathrm{B}$ mode with frequent twinkling artefacts on the Doppler mode was identified in $181(36 \%)$ of the 503 patients. Univariate analysis showed that HERM associated with higher age, longer duration of gout, clinical tophi, urate arthropathy $(p<0.0001$ for each of the variables), higher uricemia $(p=0.001)$, hypertension $(p=0.0008)$, CHD $(p=0.0006)$, lower eGFR $(p<0.0001)$ leucocyturia $(p=0.02)$, proteinuria $(p=0.02)$. No association with US-diagnosed urolithiasis, hematuria, urine $\mathrm{UA} /$ creatinine ratio, $\mathrm{FCU}$ and urinary $\mathrm{pH}$ was found. In multivariate analysis, log of the duration of gout (0R: 2.22 (Cl: 1.63-3.08), $\mathrm{p}<0.001)$, clinical tophi (OR: $8.21(4.23-16.91) \mathrm{p}<0.001)$, urate arthropathy (OR: 3.74 (2.18-6.52, p<0.001), and lower eGFR (OR: $0.86(0.75-0.99)$ for each $10 \mathrm{ml} /$ min decrease, $p=0.04$ ) were significantly associated with HERM.

Conclusions: In our gout population, HERM was observed in $36 \%$ of patients, correlated with decreased renal function, and clearly associated with severe gout, but not with features of uric acic lithiasis.

Disclosure of Interest: T. Bardin Consultant for: Grunnenthal, Ipsen Menarini, Astrazeneca, NovartisSobi, K. M. Tran: None declared, Q. D. Nguyen: None declared, N. H. Le : None declared, P. Richette Consultant for: Grunnenthal, Ipsen Menarini, Astrazeneca, NovartisSobi, P. Le Van: None declared, J.-M. Correas: None declared, M. Resche-Rigon: None declared

DOI: 10.1136/annrheumdis-2018-eular.5027

\section{OP0358 WHY DO NOT ALL CHRONIC KIDNEY DISEASE PATIENTS GET GOUT? IMPAIRED NEUTROPHIL CHEMOTAXIS IN HYPERURICEMIA-RELATED CKD}

Q. Ma ${ }^{1}$, M. Sellmayr ${ }^{1}$, F. Preitner ${ }^{2}$, H.-J. Anders ${ }^{1}$, S. Steiger ${ }^{1} .{ }^{1}$ Klinikum der Universität München, Medizinische Klinik und Poliklinik IV, Nephrologisches Zentrum, München, Germany, ${ }^{2}$ University of Lausanne, Center for Integrative Genomics, Lausanne, Switzerland

Background: One characteristic feature of acute gout is the infiltration of neutrophils into the inflamed joints, where they recognise monosodium urate (MSU) crystals leading to an acute inflammatory response. The development of chronic kidney disease (CKD) is associated with increased serum uric acid (UA) levels also known as hyperuricemia, a major risk factor for gout. Despite hyperuricemia, acute gout is less frequent in CKD patients. However, the effects of hyperuricemia on leukocyte chemotaxis in CKD are not fully understood. 